\title{
Insulin pumps
}

\section{T Torrance, V Franklin, S Greene}

\section{A growing option in the UK for children and young adults with type 1 diabetes} nsulin pump therapy-continuous
subcutaneous insulin infusion (CSII) - was developed in the UK in the 1970s. Rapid technological developments changed the initial pumps from the size of a house brick, charged by mains electricity to an acceptable dimension, battery driven. We described the use of pumps in young people with type 1 diabetes (TID) in the UK in Archives of Disease in Childhood in the early 1980s. ${ }^{1}$ While countries across the world, notably the USA, continued with pump development, the UK appeared to move away from CSII, following concerns about efficacy and safety, ${ }^{2}$ and the potential financial burden on the NHS. In the past decade technology has advanced and modern pumps are now small in size (matchbox), reliable, available, and relatively affordable. Many countries throughout the world use CSII as part of the modern management and treatment of TID in children and young people, and large pump centres can be found in Germany, Holland, Belgium, and Scandinavia, as well the USA. Across all ages there are currently 20000 pumps in use in Germany and 100000 in the United States. ${ }^{3}$ At present the major centres in the UK (for example, Bournemouth and Harrogate) cater for a largely adult population, with small numbers of children and young people using insulin pumps.*

CSII delivers a variable preprogrammable basal rate of fast/rapid acting insulin via a small indwelling plastic cannula, with insulin delivered as a background basal rate with bolus doses to cover the intake of carbohydrate containing foods, and to correct high blood glucose levels. This system of insulin delivery appears to offer not only improvement in metabolic control, but also increased physiological and psychological wellbeing. ${ }^{4}$

\section{WHY CHOOSE PUMP THERAPY IN CHILDREN AND ADOLESCENTS?}

Overall glycaemic control in young people across the world is poor and this has had a major influence on the growing interest in pump therapy, resulting in an increase in the use of CSII; $25 \%$ of young people treated in the USA currently use this form of therapy. The Diabetes Control and Complication Trial (DCCT) ${ }^{67}$ showed that maintaining glycaemic control at an average $\mathrm{HbA}_{\mathrm{lc}}$ of $8.1 \%$ in adolescents (13-17 years) reduced the risk of retinopathy by $53 \%$ and progression of established retinopathy by $70 \%$. Importantly, the DCCT also showed that the rise of retinopathy for a given mean $\mathrm{HbA}_{1 \mathrm{c}}$ was significantly lower in the intensively treated group, suggesting this form of therapy produces less glycaemic excursion, lowering the risk of complications. ${ }^{8}$ Within the intensively treated group $42 \%$ of patients were using pumps by the end of the study and no one voluntarily withdrew. The Hvidøre Study Group ${ }^{9}$ investigated intensive insulin treatment in 22 paediatric departments in 18 countries in the late 1990s. Most of the patients were from Europe and very few were receiving CSII. Mean $\mathrm{HbA}_{\mathrm{Ic}}$ results for the group were less than optimal at $8.6 \%$ (normal range $4.4-6.3 \%$ ), and no relation was found between insulin frequency and glycaemic control, even for more than

*There are several pump manufacturers worldwide. Currently, two UK based companies (Disetronic Medical and Medtronic) are servicing an estimated 1000 patients, with other companies entering the market (see table 1). The majority of these patients are adults with TID. Experience of using pumps and training healthcare professionals (HCP) in their use in the UK is patchy across all patient age ranges. There are only a handful of centres with experience of providing young people $(<18$ years age) with pump training. The present official policy from the Department of Health on pump funding states: "Although pumps are not in wide use across the country, if resources allow, hospita consultants may prescribe insulin pumps as part of NHS treatment". Funding of CSII in the UK, therefore, depends on where people live, and many families are fully funding all pump costs independently. Further information about funding and obtaining funding for CSIl can be obtained from www.insulin-pumpers.org.uk/ukfunding. The National Institute for Clinical Excellence (NICE) published recently (April 2003) a Health Technology Assessment on insulin Pumps ("Diabetes insulin pump therapy $57^{\prime \prime}$ ), with recent "Guidance on the use of continuous subcutaneous insulin infusion for diabetes" (September 2003). See www.nice.org.uk.

four injections per day ("basal/bolus" multiple daily injection (MDI) regimen). Less than a third of patients had an $\mathrm{HbA}_{\mathrm{lc}}$ level of $<8 \%$ despite a multidisciplinary team approach with an aim of tight glycaemic control. Other studies have shown a marginal benefit in glycaemia for children and young people using CSII compared with multiple injections. ${ }^{10}$ Pickup in a recent systematic review stated that CSII does produce the "best consistent glycaemic control" over time, although this amounts to an improvement on average of $0.5 \% \mathrm{HbA}_{\mathrm{lc}}{ }^{11}$

One of the most important conclusions from these studies, together with other observational studies on patients' health beliefs and acceptance of management strategies ${ }^{12}$ is that intensifying insulin therapy on its own is insufficient. Support, education, and, we would suggest, assimilation and response to treatment must also be included, if it is to be successful; this has been clearly stated in the Scottish Intercollegiate Guideline Network (SIGN) guidelines on the management of TID in children and adolescents. ${ }^{13}$

The Scottish Study Group for the Care of the Young Diabetic (SSGCYD) has, through a national audit (DIABAUD), showed a change in management of paediatric patients across Scotland over the past 10 years, with a significant increase in the use of three or more insulin injections per day, although average $\mathrm{HbA}_{\mathrm{lc}}$ across the country did not appear to change. ${ }^{14}$ Centres achieving optimal glycaemia for their patients provided a support package of frequent patient contact (medical and nursing), at least monthly formal advice, rapid troubleshooting, and frequent changes to insulin dose and regimens. This audit suggested that the style and utilisation of resources are an important consideration when trying to intensify metabolic control; this would include CSII.

\section{WHAT IS THE IDEAL MODEL FOR INTENSIVE DIABETES THERAPY?}

We would suggest that an individual approach is adopted for each patient, asking him or her to regulate their diabetes on a day to day basis, and indeed throughout the day. Insulin can be delivered either as multiple daily injections or by CSII, with adjustments made with any substantial intake of carbohydrate ("carb counting") or change in exercise pattern. The patient needs to assimilate information from frequent blood glucose testing, the dose

Abbreviations: CSII, continuous subcutaneous insulin infusion; DKA, diabetic ketoacidosis; DSN, diabetic specialist nurse; HCP, healthcare professional; $\mathrm{MDI}$ multiple daily injection; $\mathrm{QOL}$, quality of life; TID, type 1 diabetes 
Table 1 Details of the insulin pumps currently available in the UK

\begin{tabular}{|c|c|c|}
\hline Manufacturer & Type of pump & Particulars \\
\hline \multirow[t]{2}{*}{$\begin{array}{l}\text { Disetronic Medical } \\
\text { Systems Ltd }\end{array}$} & $\mathrm{H}$-TRON Plus insulin pump & $\begin{array}{l}\text { Pump type V: a variable rate pump. The basal rate can be programmed for each hour } \\
\text { according to individual needs. Currently the most commonly used pump. } \\
\text { Pump type C: this pump delivers a constant basal rate over } 24 \text { hours. } \\
\text { Pump type D: this pump offers two different basal rates, and can be programmed for two } \\
\text { adjustable time blocks over } 24 \text { hours. } \\
\text { All the above pumps use } 3 \mathrm{ml} \text { cartridges, which need to be filled by the pump user. }\end{array}$ \\
\hline & D-TRON insulin pump & $\begin{array}{l}\text { This pump uses } 3 \mathrm{ml} \text { prefilled cartridges, has three bolus alternatives, two basal profiles, } \\
24 \text { hour basal rates, menu driven. } \\
\text { All Disetronic pumps have a preprogrammed life of two years. The pump is then returned } \\
\text { to the company for an electronics check. }\end{array}$ \\
\hline Medtronic Ltd & The Minimed 508 insulin pump & $\begin{array}{l}\text { This pump offers alert options (vibrates or beeps), three bolus types, basal flexibility, can } \\
\text { be set on the half hour, remote control option. } \\
\text { All Medtronic pumps have a four year warranty. }\end{array}$ \\
\hline Animas & $R-1000$ & $\begin{array}{l}\text { Slightly thinner and wider than other pumps delivering basal increments every three } \\
\text { minutes regardless of basal rate. Basal adjustments can be made in precise } 0.05 \mathrm{U} / \mathrm{h} \\
\text { steps rather than } 0.1 \mathrm{U} / \mathrm{h} \text {, which is ideal for children and adults who require less than } 25- \\
30 \text { units of insulin a day. } \\
\text { Four distinct basal profiles to be programmed to match lifestyle variations such as } \\
\text { dayshifts, weekends, marathon runs, or menses. }\end{array}$ \\
\hline Sooil & Dana Diabecare II & $\begin{array}{l}\text { Lightest and smallest pump available. The menus are icon driven with a large display } \\
\text { screen, although the screen resolution is not great. Power is derived from a single } \\
\text { proprietary } 3.6 \mathrm{~V} \text { battery which lasts } 2-3 \text { months. } \\
\text { Unique features include preset meal boluses, a Guided Management approach where a } \\
\text { pump lockout can be set for children, or a } 30 \text { minute melody reminder can be set } \\
\text { following boluses. } \\
\text { A current disadvantage is that the pump has a proprietary reverse luer lock connection } \\
\text { between infusion sets and the hub, so only Dana infusion sets will work with this pump. }\end{array}$ \\
\hline
\end{tabular}

Further details of other type of pumps available thoughout the world can be found at the following website: http://www.diabetesnet.com/diabetes_technology/ insulinpumps.php.

of insulin injected, and any change in "lifestyle". They can then think about and decide their own treatment strategy. We describe this as "digital diabetes". This contrasts with "trend diabetes" management, where the clinical outcome is assessed (routine clinic review, growth, and episodes of acute problems of diabetes (episodes of hypoglycaemia and diabetic ketoacidosis, DKA)), together with regular $\mathrm{HbA}_{\mathrm{lc}}$ and capillary blood glucose estimations over time (usually weeks and months), with subsequent adjustments to the insulin therapy and diet made on an intermittent basis. Digital diabetes requires major effort and input from the patients and CSII appears to be useful in this context. Limited studies suggest that the best control comes in using this approach with CSII. ${ }^{15}$

\section{EFFICACY AND SAFETY OF CSII}

There have been a number of concerns raised over the years about the efficacy and safety of insulin pumps. ${ }^{16}$ Modern pumps are more reliable than earlier models, with features including continuous safety checks, dual microprocessors, systems error detection, occlusion detection, and remaining insulin counter; they can be programmed to deliver a maximum bolus and basal rate to avoid overdose, and the memory within the pump will provide the user with information about their basal and bolus delivery for the past 24 hours and longer. Occlusions both of the lines and at the cannula site remain a problem, as the pump may not detect an interruption in insulin delivery for several hours. This could and has in the past led to concerns about DKA. Careful education, regular reinforcement of these dangers, and supervision of patients and carers can help minimise these dangers.

\section{HYPOGLYCAEMIA AND DIABETIC KETOACIDOSIS}

Hypoglycaemia can have a profound effect on children, young people, and their care providers, with a fear of "hypos" reported by as many as one in five teenagers as a reason for poor glycaemic control and abnormal insulin behaviour. ${ }^{17} \mathrm{~A}$ concern of intensive therapy was an increased risk of "hypos", and in the intensively treated group of the DCCT there was initially a threefold increase in hypoglycaemia. ${ }^{7}$ Similarly, severe nocturnal hypoglycaemia has been shown to be a frequent complication of MDI and CSII. ${ }^{18}$ However, evidence suggests that with experience and increasing expertise the risk of hypoglycaemia is no higher than with conventional therapy. The rate of hypoglycaemia in the DCCT decreased significantly as the study progressed, ${ }^{7}$ and subsequent studies using MDI and CSII to tighten glycaemic control have failed to raise a concern of a higher rate of hypoglycaemia. Recently Boland and colleagues $^{5}$ studied a group of young people using MDI and CSII, and showed a reduction in severe hypoglycaemia of $50 \%$ with improvement in glycaemic control, self efficacy, depression, and quality of life (QOL) in both MDI and CSII. Adolescents using CSII developed better coping strategies than those using MDI. Rudolf et al had reported similar findings in 1982. ${ }^{19}$ Various groups now advocate the combination of intensification of insulin therapy (MDI or CSII) with behaviour modification strategies (for example, increasing self efficacy, problem solving) as well as intensive education programmes around the risks of CSII. ${ }^{20-22}$

DKA in children and young people, when compared to an adult population, is often associated with several factors: abnormal psychosocial behaviour, puberty growth spurt, alcohol, and compliance with therapy. ${ }^{23}$ Notwithstanding these concerns, the incidence of DKA is reported as being the same using either CSII or MDI. ${ }^{24}$ The rate of DKA decreases with the experience of using pumps, with a low incidence of DKA reported in children and young people in large pump centres, and the most frequent episodes reported when patients are new to the therapy. ${ }^{25}$

\section{OVERNIGHT GLYCAEMIC CONTROL}

A major difficulty in the use of both standard insulin therapy and MDI is in the effectiveness of controlling the night time blood glucose level, ${ }^{26}$ with the difficulty during sleep of matching the appropriate insulin with blood glucose concentration. The instability is increased further with the release of overnight counter regulatory hormones, resulting frequently in increased blood 
sugars on rising-the dawn phenomenon. In theory, adjustable overnight insulin via a pump should improve nocturnal and early morning glycaemic control. Kaufman and colleagues, ${ }^{27}$ in a randomised trial, compared the novel intermediate acting insulin (NPH) plus a rapid acting insulin (Lispro) before breakfast, with three injections per day in a group of children, as a way of improving glycaemic control; CSII resulted in lower breakfast blood glucose readings within the target range of 4-9 mmol. This study was particularly important as it was the first study to use night time CSII exclusively on children.

\section{RECENT PUMP EXPERIENCE IN TAYSIDE}

With the increasing use of pumps in young people across the world and an increasing interest being shown by some of our patients, we embarked recently on a programme of pump therapy in our clinic. Initially this was on an ad hoc basis to gain experience and this has led us on to the use of pumps in an ongoing randomised control trial of a novel social support package for intensive therapy using mobile phone technology ("Sweet Talk"). Our experiences outlined here are from the first use of CSII in the Tayside Paediatric Diabetes Service.

\section{Which patients to select?}

There are a number of selection criteria that have been advocated for the patient who wishes to use an insulin pump:28 MDI for at least six months; compliance with instructions given on diet and exercise; high $\mathrm{HbA}_{\mathrm{lc}}$ with strong motivation to improve control; and high scores on a Gameboy have all been cited. Our experience in Tayside has use of night time CSII and a mixture of

shown that there are a number of patients who achieve improvements in glycaemia, but who would not fulfil these selection criteria. Our view was to allow pump use in patients who wanted to try and who thought it would improve glycaemic control. Initially we approached patients who the diabetes team thought would do well; subsequently we asked patients who had had poor glycaemic control for several years and who had failed to respond to other changes in management. Few of the young people were blood testing four times daily prior to starting insulin therapy; this was, however, a prerequisite of selection.

\section{Which insulin to use?}

We choose to use a rapid acting analogue insulin (Novorapid), which when injected subcutaneously has a more rapid onset and shorter duration of action compared with soluble insulin. Improved glycaemic control and reduction in hypoglycaemia has been reported with Lispro insulin in CSII; ${ }^{31}$ it appears safe and may improve postprandial excursions. ${ }^{32}$ Caution must, however be advised as metabolic decompensation after interruption of CSII may be brisk.

\section{Attaching the pump}

The pump was attached to an infusion set by an infusion line. After removing the needle insert a small soft, flexible, plastic cannula was left in situ in the subcutaneous space (usually in the abdomen, upper arm, buttock, or upper thigh); it was fixed by self adhesive tape and connected to the insulin reservoir on the pump by a length of double walled infusion line $(30,60,80$, or $120 \mathrm{~cm}$ in length) (see fig 1). This is

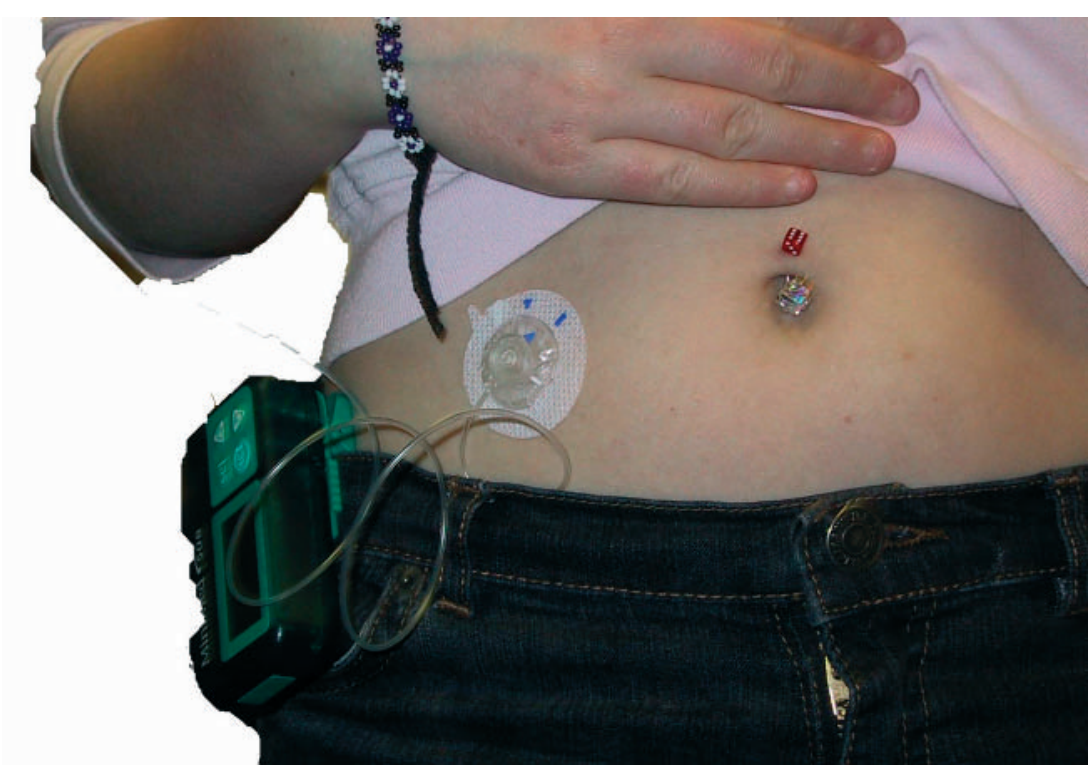

Figure 1 Photograph of pump system in situ. usually coiled under clothes during wear. Patients choose from a variety of infusion sets with different types of needle introducers and residual cannula and various ways of fixing by adhesive. We recommended that the cannula be left in place for two days (although in our experience many children will leave them for up to four days for convenience), and that sites should be rotated frequently. Occasionally the cannulae became "sore", needing to be removed within several hours. The cannulae often left small red marks on the skin that may persist for several weeks; we found that application of tea tree oil helped the healing. We offered a variety of pouches and cases for carrying the pump, which were worn on the belt or in the pocket, although fashion conscious teenagers often devised their own ingenious ways of "wearing the pump". We allowed pumps to be worn for normal rough and tumble events (for example, spontaneous games of kick about football, dancing, or skipping), but for more formal sporting activities we suggested detaching the pump for up to one and half hours and securing the cannula with extra tape. Although most pumps are water resistant, we recommended that they be removed for water sports. For showering, we advised disconnection of the pump, or placing in a waterproof bag hung around the neck.

\section{Insulin dose and basal rates}

There are a variety of guidelines available for the calculation of basal and bolus rates from the pump manufacturers. We started by reducing the prepump daily insulin requirement by $25 \%$, to allow for insulin sensitivity, which is normally increased with CSII and the use of fast/rapid acting insulin. Basal rates were calculated as either $50 \%$ of the "new pump" dose, or 0.22 units $/ \mathrm{kg}$ / day. This is, however, the lower end of the expected dose and was likely to change over the first few weeks of pump therapy. The Disetronic pump (H-TRON, D-TRON) has the facility to programme a variable hourly basal rate over the 24 hour period. The Medtronic pump can be programmed for a number of basal rates, but in practice 2-4 are usually selected. Bolus doses are linked to the carbohydrate intake at meal times, and we suggested a bolus if more than 10 grams were ingested. The remaining $50 \%$ of insulin dose was split between the meals depending on carbohydrate intake, but titration of the bolus dose against blood glucose response was an important feature of the first few weeks of pump therapy. Hence the need to perform frequent blood glucose tests and "count carbohydrate". Guidelines for insulin dose in CSII are based on 


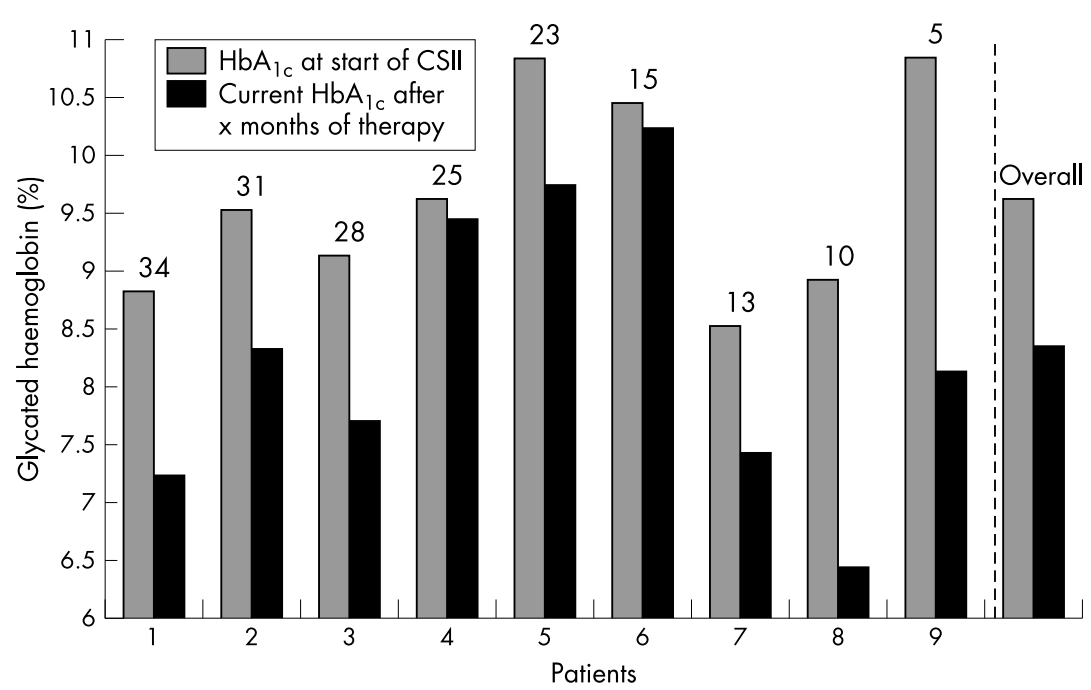

Figure 2 Improvement in glycaemic control $(\mathrm{HbAlc})$ in patients continuing treatment with insulin pump therapy $(n=9)$. Duration of therapy shown for each patient (range 5-34 months therapy). Overall mean $\mathrm{HbAlc}$ : $9.6 \%$ to $8.3 \%$.

adults and do not necessarily apply to children. Very young children may require a further reduction in insulin dose, whereas there may be no need to reduce pre-pump insulin requirements on changing to CSII in pubertal patients with insulin resistance. Basal rates for children may be more accurate at 40 $45 \%$ of the total daily dose, with the maximum rate occurring in the late evening in prepubertal children. ${ }^{29}$

\section{Pump training}

We tried were possible to train young people in groups, to provide peer support, and allow parents and friends to be involved. The training was provided over a half day by a consultant, dietician, and diabetes specialist nurse (DSN), and ended with lunch. We used various mediums for training and learning (videos, flipcharts, and written instruction) and the young people were encouraged to be active participants, helping each other to site the cannula and working out their initial basal rates and carbohydrate exchanges. The training included information on all aspects of hypoglycaemia, DKA, and dietary instruction. All patients were issued with machines to measure blood glucose and ketones, which were calibrated and checked. Hypostop and glucagon were supplied. The young people were provided with 24 hour contact numbers and were telephoned twice daily for the first week following commencement of CSII. An early clinic appointment was arranged for formal follow up.

\section{Clinical outcome}

In our first attempt to intensify glycaemic control and gain experience of using CSII, 15 young people (10-16 years of age) were put on to CSII over a 28 month period. Five patients stopped pump therapy after varying periods $(<2$ days to 22 months); their initial $\mathrm{HbA}_{\mathrm{lc}}$ values have not changed on reverting to standard therapy (average $10.8 \%$ to $10.3 \%)$. This high discontinuation rate (33\%) probably related to a lack of experience on our part and unsuitable choice of patients. Continuation with pump therapy in our patients was affected by low estimation of ability to control and treat diabetes with the pump, erythema at their injection sites, and a low level of commitment and involvement with the therapy. These appear to have all been identified previously as risk factors for stopping CSII. ${ }^{29}$

All patients who remain on CSII are happy and do not wish to revert to conventional therapy, including one boy with major multiple autoimmune disease (Evan syndrome and autoimmune malabsorption, alopecia, and TID). In these nine patients $\mathrm{HbA}_{\mathrm{lc}}$ fell in all cases with a reduction in mean $\mathrm{HbA}_{1 \mathrm{c}}$ of $9.6 \%$ to $8.3 \%$ (see fig 2 ).

In all patients there was a significant reduction in daily insulin dose (range 25-60\%), and with no abnormal effect on weight or BMI, except in one boy who used his pump to allow extra food intake and yet keep good blood glucose control. No additional hypoglycaemia was noted. One patient was admitted to hospital with DKA following poor compliance with the pump routine; she subsequently stopped using the pump

\section{Troubleshooting}

Several practical problems arise with continuing pump therapy. Batteries may not always be reliable and patients should always have spares available. The health professionals involved in supporting the patients should also have access to spares. Cannula dislodgement in our experience was a particular problem in lean active young men; this improved with additional taping of the cannula (Opsite) or by using different sites of insertion (for example, buttocks) or with different pump cases and belts. Cannula occlusion occurred on only one occasion when unbuffered insulin (Actrapid) was used in the pump; this resolved on changing to buffered insulin (Novorapid). Transfer of patients to other health professionals (locally and outside the region) was a particular problem, with major concerns expressed by the new clinical team due to lack of familiarity of pumps. To

Table 2 Current projected costs of insulin pump therapy*

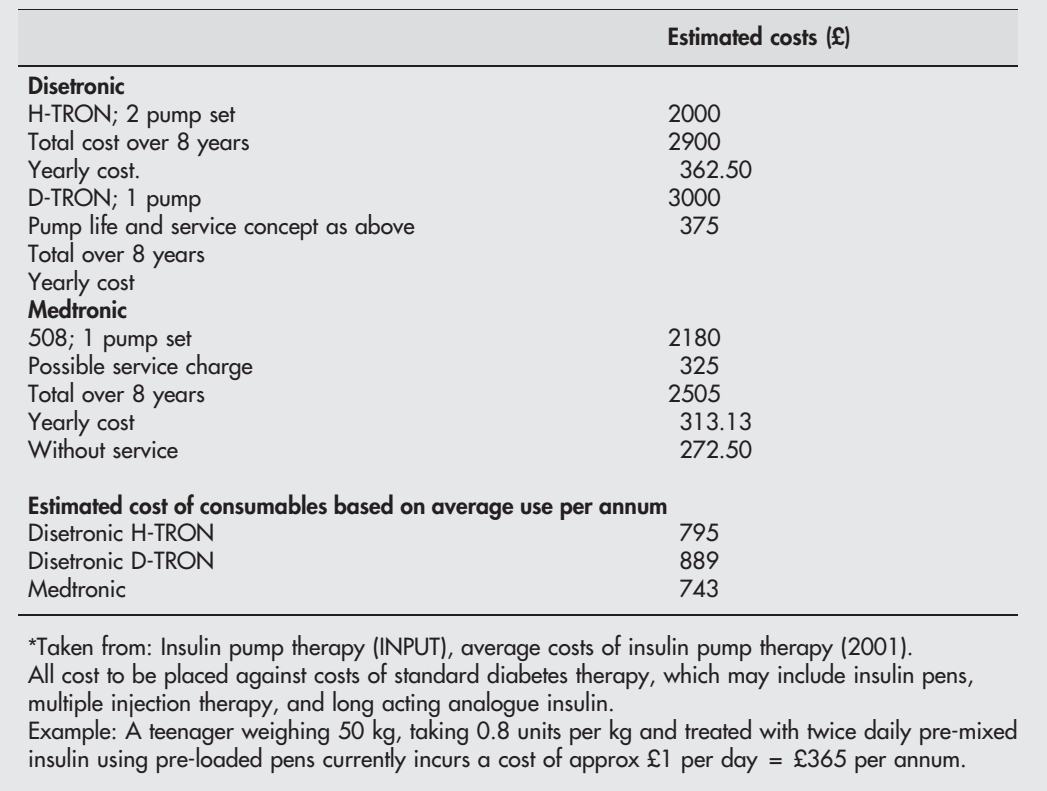


overcome these problems a DSN and consultant familiar with pump therapy currently provide a "24 hour on-call" service. The manufactures also supply a "patient help line". The patients are encouraged to keep in contact regularly using the telephone, email, and frequent clinic attendance.

\section{Funding}

This has and continues to be a major problem. Initial funding of the pumps and their disposables (in the first year) was from one of the pump manufacturers. Subsequently, funding has been obtained from several sources to continue the therapy in those patients started on pumps: financing from the paediatric clinical budget; local charity donations; and private funding by individual families. Patients requesting pump therapy are made aware of the funding problems, and at present new patients are commenced on CSII only as part of a randomised control trial studying the effect of an IT technology driven support service on the uptake of intensive insulin therapy-"the Sweet Talk Project". Details of the cost of pump therapy are currently being presented to our local Diabetes Advisory Group and the Health Board (see table 2).

\section{CONCLUSION}

Our recent experience in Tayside has been very positive. We have a steady stream of enquiries about CSII therapy and a significant number of patients wish to use an insulin pump. As with any therapy there are a number of advantages and disadvantages. Not all children will be capable of using an insulin pump, nor would they choose to use one. The advantages of the therapy can be that it offers a more flexible lifestyle and eating pattern, while at the same time delivering insulin in a more physiological way, improving metabolic control, and successfully managing the dawn phenomenon, through flexibility of basal rates. Multiple daily injections are replaced by one injection every 2 4 days. Severe hypoglycaemia does not appear to be a major concern with education of the patient, and there are very positive effects of CSII on the quality of life in young people with this devastating disease process. There are of course practical disadvantages to CSII, the commonest being risk of infection at the cannula site. Some patients have psychological problems being attached to a device 24 hours per day, enforcing their negative image of diabetes; it serves as a reminder of the disease on a daily basis. ${ }^{33}$ There is a small risk of DKA, but the literature would suggest that this improves with experience of using the pump, and is more common in the early days of pump use. Perhaps the major disadvantage to CSII in this country today is the financial implications for its use.

Pump therapy appears to be a growing option for young people with TID. For those who use pumps successfully, the benefits outweigh the disadvantages and they appear to be the best method of achieving the desired target of near normal glycaemia over time, coupled with constant education and support. Pump therapy must be available as part of the management strategy offered in the UK to the young with TID.

\section{ACKNOWLEDGEMENTS}

We thank Disetronic UK Ltd and Medtronic plc for their help in our use of insulin pumps, the members of the Tayside Children Diabetes Clinic and the children and adolescents who have worked with us.

Arch Dis Child 2003;88:949-953

\section{Authors' affiliations}

T Torrance, V Franklin, S Greene, Maternal and Child Health Sciences, University of Dundee, Ninewells Hospital \& Medical School, Dundee, Scotland, UK

Correspondence to: $\operatorname{Dr} S$ Greene, Reader in Child \& Adolescent Health, Maternal and Child Health Sciences, Ninewells Hospital \& Medical School, Dundee DDI 9SY, Scotland, UK; s.a.greene@dundee.ac.uk

\section{REFERENCES}

1 Greene SA, Sith MA, Baum JD. Clinical application of insulin pumps in young adults and children with insulin dependent diabetes mellitus. Arch Dis Child 1983:58:578-81.

2 Knight G, Boulton AJ, Ward JD. Experience of continuous subcutaneous insulin infusion in the outpatient management of diabetic teenagers. Diabet Med 1986;3:82-4.

3 INPUT (insulin pump therapy). Average costs of insulin pump therapy. 2001. http:// www.geocities.com/Vienna.Strasse/5726/input. Accessed 2/8/02.

4 Tamborlane WV, Bonfig W, Boland E. Recent advances in treatment of youth with type 1 diabetes: better care through technology. Diabet Med 2001; 18:864-70.

5 Boland EA, Grey M, Oesterle A, et al. Continuous subcutaneous insulin infusion. A new way to lower risk of severe hypoglycemia, improve metabolic control, and enhance coping in adolescents with type 1 diabetes. Diabetes Care 1999;22:1779-84

6 The Diabetes Control and Complications Trial Research Group. The effect of intensive treatment of diabetes on the development and progression of long-term complications in insulin dependent diabetes mellitus. N Engl J Med 1993;329:977-86.

7 White NH, Cleary PA, Dahms W, et al. Beneficial effects of intensive therapy of diabetes during adolescence: outcomes after the conclusion of the Diabetes Control and Complications Trial (DCCT) I Pediatr 2001;139:804-12.

8 The Diabetes Control and Complications Trial Research Group. The relationship of glycemic exposure $(\mathrm{HbAlc})$ to the risk of development and progression of retinopathy in the diabetes control and complications trial. Diabetes 1995;4:968-83.

9 Mortensen HB, Marinelli K, Norgaard K et al, and the Danish Study Group of Diabetes in Childhood. A nationwide cross-sectional study of urinary albumin excretion rate, arterial blood pressure and blood glucose control in Danish children with type 1 diabetes mellitus. Diabet Med 1990;7:887-97.

10 Lenhard MJ, Reeves GD. Continuous subcutaneous insulin infusion: a comprehensive review of insulin pump therapy. Arch Intern Med $2001 ; 161: 2293-300$.

11 Pickup JC. Is insulin pump treatment justifiable? In: Gill G, Pickup J, Williams G, eds. Unstable and difficult diabetes. Oxford: Blackwell Science, 2003.

12 Greene AC, Tripaldi M, McKeirnan P, et al. Promoting empowerment in young people with type 1 diabetes. Diabet Med 1999;16(suppl 1):20.

13 Scottish Intercollegiate Guideline Network (SIGN). Children and young people. Publication 55. Scottish Executive. 2001

14 Scottish Study Group for the Care of the Young Diabetic. Factors influencing glycaemic control in young people with type 1 diabetes in Scotland: a population based study (Diabaud2). Diabetes Care 2001;24:239-44.

15 Pickup J, Keen H. Continuous subcutaneous insulin infusion in type 1 diabetes. BMJ 2001;322:1262-3.

16 Pickup J, Keen H. Continuous subcutaneous insulin infusion at 25 years: evidence base for the expanding use of insulin pump therapy in type 1 Diabetes. Diabetes Care 2002;25:593-8.

17 Newton RW. Conference for young diabetics. Diabet Med 1987;4:335-6.

18 Bergada I, Suissa S, Dufresna J, et al. Severe hypoglycaemia in IDMM children. Diabetes Care 1989:12:239-44.

19 Rudolf MC, Ahern JA, Genel M, et al. Optimal insulin delivery in adolescents with diabetes: impact of intensive treatment on psychosocial adjustment. Diabetes Care 1982;5(suppl 1):53-7

20 Brink SJ. How to apply the experience from the diabetes control and complications trial to children and adolescents? Ann Med 1997:5:425-38.

21 Bogestig M, Arnqvist HJ, Hermansson G, et al. Declining incidence of neuropathy in insulin dependent diabetes mellitus. $N$ Engl J Med 1994;330:15-18

22 Dorchy $\mathrm{H}$. What glycaemic control can be obtained in young diabetics without residual endogenous insulin secretion? What is the frequency of hypoglycaemia and subclinical complications? Arch Paediatr 1994;1:970-81.

23 Greene SA. Diabetes in childhood and adolescence. In: Pickup J, Williams G, eds. Textbook of diabetes, 2nd edn. Oxford: Blackwell Science, 1997.

24 Pickup J, Mattock M, Kerry S. Glycaemic control with continuous subcutaneous insulin infusion compared with intensive insulin injections in patients with type 1 diabetes: meta-analysis of randomised controlled trials. BMJ 2002;324:705.

25 Hanas R. Selection for and initiation of continuous subcutaneous insulin infusion. Proceedings from a workshop. Horm Res 2002;57(suppl 1):101-4.

26 Matyka KA, Crawford C, Wiggs L, et al. Alterations in sleep physiology in young children with insulin-dependent diabetes mellitus: relationship to nocturnal hypoglycemia. J Pediatr 2000; 137:233-8

27 Kaufman FR, Halvorson M, Kim C, et al. Use of insulin pump therapy at nighttime only for children 7-10 years of age with type 1 diabetes. Diabetes Care 2000 May:23:579-82.

28 Wredling RA, Adamson UK, Lins PE. Alteration of the risk factor paradigm for discontinuance of insulin pump therapy. Diabetes Care 1994; 17:942-3.

29 Bode B, Weinstein R, Bell D, et al. Comparison of insulin aspart with buffered regular insulin and insulin lispro in continuous subcutaneous insulin infusion: a randomized study in type 1 diabetes. Diabetes Care 2002;25:439-44.

30 Bode BW, Tamborlane WV, Davidson PC. Insulin pump therapy in the 21 st century. Strategies for successful use in adults, adolescents, and children with diabetes. Postgrad Med 2002:111:69-77.

31 Schmauss S, Konig A, Landgraf R. Human insulin analogue [LYS(B28), PRO(B29)]: the ideal pump insulin? Diabet Med 1998;15:247-9.

32 Conrad SC, McGrath MT, Gitelman SE. Transition from multiple daily injections to continuous subcutaneous insulin infusion in type 1 diabetes mellitus. J Pediatr 2002;140:235-40.

33 Stein C. Psychological reactions to insulin infusion pumps. Med Clin North Am 1982;66:1285-92. 